\title{
Dissolution enhancement of chlorzoxazone using cogrinding technique
}

\author{
Mihir K. Raval ${ }^{1}$, Jaydeep M. Patel ${ }^{1}$, Rajesh K. Parikh ${ }^{2}$, Navin R. Sheth ${ }^{1}$ \\ ${ }^{1}$ Department of Pharmaceutical Sciences, Saurashtra University, Rajkot, ${ }^{2}$ Department of Pharmaceutical Technology, L. M. College \\ of Pharmacy, Navrangpura, Ahmedabad, Gujarat, India
}

\begin{abstract}
Purpose: The aim of the present work was to improve rate of dissolution and processing parameters of BCS class II drug, chlorzoxazone using cogrinding technique in the presence of different excipients as a carrier. Materials and Methods: The drug was coground with various carriers like polyethylene glycol (PEG 4000), hydroxypropyl methylcellulose (HPMC) E50LV, polyvinylpyrrolidone (PVP)K30, Kaolin and Neusilin US2 using ball mill, where only PEG 4000 improved dissolution rate of drug by bringing amorphization in 1:3 ratio. The coground mixture after 3 and $6 \mathrm{~h}$ was evaluated for various analytical, physicochemical and mechanical parameters. Results: The analysis showed conversion of Chlorzoxazone from its crystalline to amorphization form upon grinding with PEG 4000. Coground mixture as well as its directly compressed tablet showed 2.5-fold increment in the dissolution rate compared with pure drug. Directly compressible tablets prepared from pure drug required a large quantity of microcrystalline cellulose (MCC) during compression. The coground mixture and formulation was found stable in nature even after storage $\left(40^{\circ} \mathrm{C} / 75 \%\right.$ relative humidity). Conclusions: Cogrinding can be successfully utilized to improve the rate of dissolution of poorly water soluble drugs and hence bioavailability.
\end{abstract}

Key words: Amorphization, chlorzoxazone, cogrinding, dissolution enhancement, heckel analysis

\section{INTRODUCTION}

Majority of crystalline Active Pharmaceutical Ingredients have poor aqueous solubility due to which rate of drug dissolution becomes very low. ${ }^{[1]}$ It ultimately leads to the bioavailability problems of the drug. Rate of drug dissolution is affected by many other factors such as surface area, crystallinity, wettability, etc. ${ }^{[2]}$ It may create a requirement of high dose of the drug in order to exert required pharmacological response. ${ }^{[3]}$ Improvement in rate and extent of dissolution is highly desirable for such compounds that have dissolution rate limited bioavailability. There are various techniques utilized to enhance the rate and extent of dissolution like amorphization by milling, complexation, solid dispersion, spray drying, etc. ${ }^{[4-6]}$ Particle size reduction without

\section{Address for correspondence:}

Dr. Mihir K. Raval,

Department of Pharmaceutical Sciences, Saurashtra University,

Rajkot - 360 005, Gujarat, India.

E-mail: rmihir@yahoo.com

\begin{tabular}{|l|l|}
\hline \multicolumn{2}{|c|}{ Access this article online } \\
\hline Quick Response Code: & Website: \\
\hline & www.jpionline.org \\
\cline { 2 - 2 } & DOI: \\
\hline
\end{tabular}

using a solvent system can be achieved by milling process. Milling can exert mechanical stress on the crystalline particles of drug and generate defects in its crystalline structures, which may lead to amorphous region on its surface. ${ }^{[7]}$ Due to the formation of amorphous regions on the surface of crystalline materials, instability of crystalline material increases and again gets transformed to a stable crystalline state. ${ }^{[8]}$ Stability of this amorphous region is very essential for maintaining the achieved enhancement of dissolution property. Here, a selection of carrier is very important, which can stabilize the amorphous drug and prevent its transformation. ${ }^{[9]}$ Various carriers are reported in the literature for the process of cogrinding like Neusilin US2, polyvinylpyrrolidone (PVP), cyclodextrins, etc. ${ }^{[7,9-11]}$ Vogt et al. found that lactose and PVP enhanced dissolution of fenofibrate by its ball milling. They also studied an influence of lactose monohydrate (LMH), corn starch, PVP, hydroxypropyl methylcellulose (HPMC) and sodium lauryl sulfate on dissolution rate enhancement of four poorly soluble drugs (EMD 57033, albendazole, danazol and felodipine) by their cogrinding.

${ }^{[1]}$ Balani et al. observed improvement in dissolution rate of Salbutamol Sulfate (SS) by its ball milling with LMH. They also concluded that LMH could also retain the crystallinity of coground SS even after stability study, which was not maintained in simply ground SS ${ }^{[8]}$ Hence, cogrinding of drug with suitable excipients can not only improve the dissolution rate of drug, but also stabilize the amorphous nature of coground drugs. Apart from the improved dissolution property, mechanical property of the material under process is highly desired to generate a robust 
formulation. ${ }^{[4]}$ As per our survey, either no or very few scientists have worked on amorphization of drug using ball mill and converted it to a stable and directly compressible formulation. Chlorzoxazone (5-chloro-2,3-dihydro-1,3-benzoxazol-2-one), a centrally acting central muscle relaxant with sedative properties, is a poorly water soluble drug $(0.2-0.3 \mathrm{mg} / \mathrm{ml})$. It is highly cohesive powder with very poor flow property, and compressibility, hence wet granulation is the only option for manufacturing of conventional tablets. ${ }^{[12-14]}$ Polyethylene glycol 4000 (PEG 4000) is a hydrophilic polymer, which is widely used for the formation of solid dispersion. ${ }^{[15]}$ However, there are many disadvantages of solid dispersion, such as moisture and temperature have more of deteriorating effect on solid dispersions than on physical mixtures (here, cogrinding is like a dry physical mixture only). Sometimes, it is difficult to handle because of tackiness. ${ }^{[16]}$ All methods of preparation are not applicable for every type of drugs and polymers. Moreover, only few solvents are applicable for the process due to regulatory constraints. The present study focuses on improvement of dissolution rate of poorly water-soluble drug chlorzoxazone by bringing amorphization using ball mill and utilizing the coground mixture as a directly compressible intermediate to prepare tablets. Here, chlorzoxazone is selected as a model drug showing poor physicochemical and mechanical property.

\section{MATERIALS AND METHODS}

\section{Materials}

Chlorzoxazone USP was procured from Arti Drugs Ltd., Mumbai, India. PEG 4000 IP was purchased from Merck Pvt. Ltd., Mumbai, India. HPMC E50LV IP and kaolin IP were procured from Loba Chemie Pvt. Ltd., Mumbai, India. PVP K30 IP was procured from Sisco Research Laboratory Pvt. Ltd., Mumbai, India. Neusilin US2 BP was gifted by Gangwal chemicals Pvt. Ltd., Mumbai, India. All other solvents and chemicals used were of analytical grade (Merck Pvt. Ltd., Mumbai, India). Double distilled water was used for the entire study.

\section{Preparation of coground mixture}

A powder mixture comprising of chlorzoxazone and various carriers like Neusilin US2, Kaolin, PEG 4000, HPMC E50LV and PVP K30 in a specific weight ratio (1:3 and 1:5) was milled using ball mill having five small balls with outer diameter of 19.04 $\mathrm{mm}$ and five large balls with outer diameter of $25.37 \mathrm{~mm}$ (all were made up of stainless steel) for $1 \mathrm{~h}$ (Cronimach Machinery Pvt., Ltd., Ahmedabad, India). ${ }^{[17]}$ Dissolution study was done to optimize an effective carrier. After that, the drug was milled with optimized carrier and in a specific weight ratio for an extended period until the enhancement in dissolution rate was resulted. The speed of cylindrical jar was maintained at $65 \mathrm{rpm}$, in a way to allow significant attrition with some impact. Milling was performed in the cold chamber to avoid any effect of heat generation on the mixture. Milled material was sieved through ASTM standard mesh no. 60 (300 $\mu \mathrm{m}$ opening). To ascertain the influence of method, carrier or both on the improvement of dissolution rate, drug alone was ground for an extended period (control batch). All samples were stored in glass vials at room temperature until used for the further analysis. One batch from optimized sample was also kept for 6 months stability study in screw capped container. ${ }^{[18,19]}$

\section{Packability and flow parameters}

For the rheological characterization of the prepared mixture; angle of repose, Carr's index and Hausner's ratio were measured. Angle of repose was determined using fixed funnel method. ${ }^{[20,21]}$ Percentage compressibility (Carr's Index) and Hausner's ratio were calculated after tapping of fixed amount of the ground mixture using USP type tap density tester (ETD-1020, Electrolab, Mumbai, India). ${ }^{[22]}$ Packability parameters like 'a' (compressibility, or amount of densification due to tapping), '1/b' (cohesiveness, or how fast/easily the final packing state was achieved) and 'K' (Kuno's constant was determined directly by putting the values of densities) were calculated using Kawakita and Kuno's equations at taps 10, 30, 50, 100, 200 and 300. ${ }^{[23-27]}$ The values of ' $a$ ' and ' $b$ ' were calculated from the slope and intercept of the linear plot of $\mathrm{N} / \mathrm{C}$ versus $\mathrm{N}$, respectively.

Kawakita equation: $\frac{N}{C}=\frac{1}{a b}+\frac{N}{a}$

Here, $\mathrm{Y}=\mathrm{N} / \mathrm{C}, \mathrm{m}$ (slope) $=1 / \mathrm{a}$ and $\mathrm{c}($ intercept $)=1 / \mathrm{ab}{ }^{[28]}$

Where, $C=\frac{\left(V_{0}-V_{\mathrm{n}}\right)}{V_{0}}$

Kuno's equation: In $\left(\mathrm{q}_{\mathrm{t}}-\mathrm{q}_{\mathrm{n}}\right)=-\mathrm{K}_{\mathrm{n}}+\ln \left(\mathrm{q}_{\mathrm{t}}-\mathrm{q}_{0}\right)$

Where, $\mathrm{N}$ is number of tapping

$\mathrm{V}_{0}$ and $\mathrm{V}_{\mathrm{n}}$ are initial volume and volume after 'n' no. of taps, $\mathrm{q}_{0}$ $\mathrm{q}_{\mathrm{n}}$ and $\mathrm{q}_{\mathrm{t}}$ are the initial density, density at ' $\mathrm{n}$ ' taps and density at infinite taps, respectively.

$\mathrm{a}, \mathrm{b}$ and $\mathrm{K}$ are the constants representing flowability and packability of powder under mechanical force. The smaller the values of parameters ' $a$ ' and ' $1 / \mathrm{b}$ ' in Kawakita equation for samples indicated higher packabilities compared with pure chlorzoxazone. Higher values of parameter 'K' in Kuno's equation for sample, was an indication of marked improvement in compressibility and packability attributed to much higher rate of their packing processes than that of pure drug due to sphericity and size reduction of particles. ${ }^{[28]}$

\section{Capillary melting point}

Mixture was filled in one end sealed capillary and melting range was determined on digital melting point apparatus (accuracy \pm $0.1^{\circ} \mathrm{C}$ ) (Veego instruments Corporation, Mumbai, India).

\section{Microscopic determination and surface topography}

Shape and size of the mixtures were observed under the optical microscope with $\times 10$ magnification (MLX-DX, Olympus [India] Pvt. Ltd., New Delhi, India) and photomicrographs 
were taken using charged couple device camera (MIPS-USB, Olympus [India] Pvt. Ltd., New Delhi, India) for comparing morphological changes in prepared coground samples and pure drug. The preliminary observation of the shape of the prepared coground mixtures was done.

\section{Drug loading efficiency and \% yield}

Drug loading efficiency is the ratio of experimentally measured drug content to the theoretical value, expressed as percentage $(\%) .^{[27,29]}$ Accurately weighed quantity of prepared ground samples were dissolved in little quantity of acetone and made the volume to $50 \mathrm{ml}$ in a volumetric flask. These solutions were appropriately diluted with phosphate buffer $\mathrm{pH} 6.8$ and drug content was determined by ultraviolet (UV) spectrophotometer using the same buffer as blank at $280 \mathrm{~nm}$.

The $\%$ yield of sample was calculated using the formula

$\%$ Yield $=\frac{\text { total weight of sample }}{\text { total weight of drug and polymer }} \times 100$

\section{Heckel plot}

Accurately weighed quantity of ground mixture ( $800 \mathrm{mg} \pm 5 \mathrm{mg}$ ) was compressed using 8 -mm flat faced punch at different force of $0.2,0.5$ and $1-9$ ton using $\mathrm{KBr}$ press (Technosearch Instruments, Mumbai, India) by keeping 1 min dwell time. ${ }^{[30]}$ The punch and die were lubricated using $1 \% \mathrm{w} / \mathrm{v}$ dispersion of magnesium stearate in acetone. The compression behavior of the samples was expressed as parameters of Heckel equation. Plot of $\ln (1 /[1-D)$ versus $\mathrm{P}$ was drawn and values of $\mathrm{K}, \mathrm{A}$ and $\sigma_{0}$ were obtained.

$\ln \left[\frac{1}{(1-D)}\right]=K P+A$

Where, $\mathrm{D}$ is a relative density of compacts, that is, ratio of compact density to true density of powder, $\mathrm{P}$ is the applied pressure, $\mathrm{K}$ is the slope of Heckel plot; $\mathrm{K}=1 / \mathrm{P}_{\mathrm{y}} \mathrm{P}_{\mathrm{y}}$ is the mean yield pressure. The constant 'A' expresses densification at low pressure. $\sigma_{0}$ is yield strength, $\sigma_{0}=1 / 3 \mathrm{~K}$. Here, density of prepared compacts for Heckel parameters was calculated from the mass to volume of compacts. True density was considered as the density of compacts when the highest pressure applied on the powder (here, 9 tons). ${ }^{[31]}$

\section{Tensile strength measurement}

After determination of diameter and thickness of compacts prepared for the study of Heckel parameters, the compacts were subjected to relaxation for $24 \mathrm{~h}$. Then the compacts were subjected to tensile strength measurement in which the force required breaking the compacts $(\mathrm{P})$ was measured using pfizer hardness tester. ${ }^{[31]}$ The tensile strength $(\mathrm{T}, \mathrm{kg})$ of the compacts was calculated using the following equation. ${ }^{[32-35]}$

$T=\frac{0.0624 \times P}{D \times L}$

Where, $\mathrm{D}$ and $\mathrm{L}$ are the diameter and thickness $(\mathrm{cm})$ of compacts, respectively. $\mathrm{P}$ is force $\left(\mathrm{kg} / \mathrm{cm}^{2}\right)$ required to break the compacts.

\section{Elastic recovery}

The compacts prepared for the Heckel plot study, and tensile strength determination was used for an elastic recovery test. The thickness of the compacts was measured immediately after ejection $\left(\mathrm{H}_{\mathrm{c}}\right)$ and after the $24 \mathrm{~h}$ relaxation period $\left(\mathrm{H}_{\mathrm{e}}\right)$. Elastic recovery was calculated using the following equation. ${ }^{[33]}$

$\% E R=([H e-H c) / H c] \times 100$

\section{Aqueous solubility study}

The solubility was determined in different solvents to correlate solubility with dissolution and bioavailability. ${ }^{[36]}$ Solubility studies were performed by adding an excess amount of coground samples to $10 \mathrm{ml}$ of solvents like distilled water, $\mathrm{pH} 1.2, \mathrm{pH}$ 4.5 and $\mathrm{pH} 6.8$ buffer solutions in specific gravity bottles until the solutions became saturated at room temperature. These specific gravity bottles were shaken for $8 \mathrm{~h}$ at $25^{\circ} \mathrm{C} \pm 1^{\circ} \mathrm{C}$ by keeping in a cryostatic constant temperature reciprocating shaker bath (Tempo Instruments and Equipments Pvt. Ltd., Mumbai, India). The same procedure was also followed for pure drug and control batch too. The bottles were then opened and centrifuged at $2000 \mathrm{rpm}$ (Remi Laboratory Instruments, Mumbai, India) for $15 \mathrm{~min}$ and supernatant liquids were separated. The absorbance of the solution was measured at $280 \mathrm{~nm}$ in UV-visible spectrophotometer (Pharmaspec - 1700, Shimadzu Corporation, Japan) by diluting with $\mathrm{pH} 6.8$ phosphate buffer. ${ }^{[28]}$ All determinations were performed in triplicate.

\section{Differential scanning calorimetry}

Thermograms of chlorzoxazone and prepared samples were performed using differential scanning calorimetry (DSC-60) (Shimadzu, Tokyo, Japan) calorimeter to study the thermal behavior of drug and prepared samples. ${ }^{[37]}$ The instrument comprised of calorimeter (DSC 60), flow controller (FCL 60), thermal analyzer (TA 60WS) and operating software (TA 60). The samples were heated at $5^{\circ} \mathrm{C} / \mathrm{min}$ heating rate in hermetically sealed aluminum pans under nitrogen atmosphere with the flow rate of $100 \mathrm{ml} / \mathrm{min}$. Empty aluminum pan was used as a reference.

\section{Fourier transform infra-red spectroscopy}

Infrared (IR) spectra of chlorzoxazone and prepared samples were recorded using IR spectrophotometer (Nicolet iS10, Thermo Fisher Scientific Inc., USA). ${ }^{[38]}$ The samples were dispersed in $\mathrm{KBr}$ and compressed into disc/pellet by application of pressure. The pellets were placed in the light path for recording the IR spectra. The spectrum was recorded.

\section{Powder X-ray diffractometry}

The X-ray powder diffraction patterns of chlorzoxazone and optimized samples were recorded using PANalytical diffractometer system (XpertproPW30-40/60) with a copper target and scintillation counter detector (voltage $40 \mathrm{kV}$; current $30 \mathrm{~mA}$; scanning speed $\left.0.05^{\circ} / \mathrm{s}\right) .{ }^{[39-41]}$ The sample holder was nonrotating and temperature of acquisition was room temperature. The diffraction pattern was analyzed in a specific $2 \theta$ range. ${ }^{[42]}$ 


\section{Scanning electron microscopy}

The shape and surface morphology were observed using scanning electron microscope (JEOL, JSM 5610 LV). ${ }^{[43]}$ The samples were observed at various magnifications to have an idea about the effect of various additives on surface treatment (morphology) and particle size.

Preparation of directly compressible tablets of chlorzoxazone and prepared mixtures

Formulation excipients were selected on the basis of preliminary tests that demonstrated no interference of these excipients at 280 $\mathrm{nm}$. Tablets equivalent to $125 \mathrm{mg}$ of chlorzoxazone were made by direct compression using different formulation excipients. Mixtures used for tabletting were having similar size range of particles. As PEG 4000 itself is a highly plastic material, wet granulation for the preparation of tablets was not required. The material for each tablet was weighed, introduced manually into the die and compressed in rotary tablet machine. The compaction surfaces were lubricated with $2 \% \mathrm{w} / \mathrm{w}$ magnesium stearate in acetone before compaction. The blend was compressed on an eight-station rotary tablet machine (Karnawati Engineering Ltd., India) to obtain tablets of required hardness and thickness. The tablets were studied in three replicates. The compacts were ejected and stored in screw-capped bottles for $24 \mathrm{~h}$ before using, to allow for possible hardening and elastic recovery. The compacts were also taken for in-process and finished product evaluation tests. The same technique was applied for the preparation of tablets of pure drug as well as tablets of the control batch.

\section{Evaluation parameters for prepared directly compressible tablets \\ Thickness and diameter of the tablets}

The thickness and diameter of individual tablet were measured with a Vernier caliper (Mitutoyo, USA), which permitted accurate measurements. The study was conducted for 20 tablets, and the average result was considered.

\section{Weight variation test of the tablets}

Twenty tablets were weighed individually, and the average weight was calculated as described in USP 29.

\section{Tablet friability test}

Tablet friability was measured by using Roche friabilator (Electrolab, Mumbai). Ten tablets were weighed and placed in the apparatus to carry out the study. The loss due to abrasion was a measure of the tablet friability.

\section{Tablet hardness test}

Tablet hardness was measured using Pfizer hardness tester. The test was done for 10 tablets and average was considered.

\section{Tablet disintegration test}

The disintegration test was carried out using the tablet disintegration tester (ED-2 L, Electrolab, Mumbai, India). The time required for the disintegration of the tablet was measured in accordance with the United States Pharmacopoeia 29. ${ }^{[4]}$
In vitro dissolution of prepared coground samples and dosage form

A USP dissolution test apparatus (TDT 06P, Electrolab, Mumbai, India) was used to monitor the dissolution profiles to evaluate the influence of process and carrier on drug release. The dissolution medium (phosphate buffer $\mathrm{pH}$ 6.8) was equilibrated to $37^{\circ} \mathrm{C} \pm 0.5^{\circ} \mathrm{C}$. Paddle and basket were rotated at $50 \mathrm{rpm}$. From the dissolution flask, $5 \mathrm{ml}$ sample was withdrawn at selected time intervals ${ }^{[42]}$ and the concentrations of chlorzoxazone in the samples were determined by UV spectrophotometer at $280 \mathrm{~nm}$ by diluting with $6.8 \mathrm{pH}$ buffer solution using same media as blank. All determinations were performed in triplicate.

\section{Dissolution parameters}

The dissolution data was analyzed by model-independent parameters calculated at different time intervals, such as dissolution percent (DP), dissolution efficiency (\%DE) and time to release $50 \%$ of the drug $(\mathrm{t} 50 \%)$. DP at different time interval and $50 \%$ can be obtained from percent dissolution versus time profile/data. ${ }^{[45-48]}$

$\%$ Dissolution efficiency (D.E.)

$\% D E=\int_{0}^{t} \frac{y \cdot d t}{y_{100} t} \times 100$

\section{Statistical analysis of dissolution profiles}

Model independent mathematical approach proposed by Moore and Flanner ${ }^{[47]}$ for calculating a similarity factor $f_{2}$ was used for comparison between dissolution profiles of different samples. ${ }^{[38]}$

$f_{2}=50 \times \log \left\lceil\left(1+\left(\frac{1}{n}\right) \sum_{\mathrm{t}=1}^{\mathrm{n}} w_{\mathrm{t}}\left(R_{\mathrm{t}}-T_{\mathrm{t}}\right)^{2}\right)^{-0.5} \times 100\right\rceil$

Where, $\mathrm{n}$ is the number of withdrawal points, $\mathrm{R}_{\mathrm{t}}$ is the percentage dissolved of reference at the time point $\mathrm{t}$ and $\mathrm{T}$ is the percentage dissolved of test at the time point t. A value of $100 \%$ for the similarity factor $\left(f_{2}\right)$ suggests that the test and reference profiles are identical. Values between 50 and 100 indicate that the dissolution profiles are similar while smaller values imply an increase in dissimilarity between release profiles. In order to understand the difference in dissolution rate of pure drug and prepared samples, the obtained dissolution data were fitted into the following equation. The same calculations were also applied for prepared dosage forms also.

$M D T_{\text {in vitro }}=\frac{\sum_{\mathrm{i}=1}^{\mathrm{n}} t_{\mathrm{mid}} \Delta M}{\sum_{\mathrm{i}=1}^{\mathrm{n}} \Delta M}$

Here, $\mathrm{i}$ is dissolution sample number, $\mathrm{n}$ is number of dissolution times, $\mathrm{t}$ and $\mathrm{t}_{\text {mid }}$ is time at the midpoint between times $\mathrm{t}_{\mathrm{i}}$ and $\mathrm{t}_{\mathrm{i}-1}$, and $\Delta \mathrm{M}$ is the amount of drug dissolved ( $\mathrm{mcg}$ ) between times $\mathrm{t}_{\mathrm{i}}$ and $\mathrm{t}_{\mathrm{i}-1}$. Mean dissolution time (MDT) reflects the time for drug to dissolve and is the first statistical moment for cumulative dissolution process that provides an accurate drug release rate. It is accurate expression for drug release rate. 


\section{Stability study}

The optimized batch was placed in $20-\mathrm{ml}$ borosilicate glass ampoule. The mouth of the ampoule was closed tightly with aluminum foil to prevent any access of air from the atmosphere to sample inside the ampoules. Six such samples were stored at $40^{\circ} \mathrm{C}$ and $75 \%$ relative humidity for 6 months. ${ }^{[18,19]}$ The dissolution behavior of sample and dosage form was evaluated in triplicate and characterized.

\section{RESULTS AND DISCUSSION}

Chlorzoxazone is a BCS Class - II drug, which has dissolution rate limited absorption. Moreover, it is a poorly compressible drug. Hence, by bringing amorphization in the drug, dissolution rate enhancement as well as directly compressible material was achieved.

\section{Preparation of coground mixture}

It was found that when rotation speed of ball mill was kept at lower rpm, the balls were falling down before the powder was. Proper mixing and milling were not observed here. When the speed was kept at higher rpm, the powder was rotating toward the direction of the shell, causing improper mixing and grinding. Hence, the rotation of ball mill was quite optimized at $65 \mathrm{rpm}$ where, proper mixing and grinding process happened together. There was no any considerable heat generation, which could affect the chemical nature of drug. It was confirmed by UV method (data not shown). Moreover, the characterizations also proved no effect of local heat generation on the chemical nature of the drug. Various excipients such as kaolin, HPMC E50LV, Neusilin US2, PVP K30 and PEG 4000 were tried by taking drug: Excipient weight ratio 1:1-1:5, but the ratio below 1:3 did not show any dissolution improvement in drug. Dissolution was carried out, followed by grinding primarily for $1 \mathrm{~h}$ in order to optimize the suitable excipient, which can enhance the rate of drug dissolution. No increase in the temperature of milled material was detected at the end of the process as it was also confirmed by content estimation (data not shown). The cumulative percentage drug release from pure drug and ground samples were studied and shown in Figure 1. It was found that the milling of drug with PEG 4000 (1:3 and 1:5 ratios) showed maximum improvement in dissolution profile $(57.55 \pm 0.51$ and $62.6 \% \pm 0.84 \%$, respectively) compared to pure drug $(37.55 \% \pm$ $0.22 \%)$, control batch $(42.58 \% \pm 0.53 \%)$ and all other carriers ( $<40 \%$ drug release). Here, both the ratios of drug: PEG 4000
(1:3 and 1:5) showed similar dissolution profile $\left(f_{2}=59.80\right)$. Looking at the overall weight of the final formulation, $1: 3$ ratio was selected for the further process. Thus, milling of drug in presence of PEG 4000 with 1:3 weight ratio was continued for longer period of time and sampling was done at fixed intervals (at every hour) followed by in vitro dissolution till the dissolution rate was improving. The milled material was sieved through ASTM standard mesh no. 60 (300 $\mu$ m opening). The physical mixture of chlorzoxazone and PEG 4000 was prepared by simple blending in a 1:3 w/w ratio (drug: Carrier) and mixed in a V-cone blender. Coground mixture of chlorzoxazone: PEG 4000 (1:3) was observed under optical microscope for evaluation of possible particle size changes after cogrinding (Figure 2). It was further evaluated for other parameters like micromeritic and mechanical properties.

\section{Packability and flow parameter study}

The samples after $3 \mathrm{~h}$ and $6 \mathrm{~h}$ grinding were selected for evaluation of micromeritic and mechanical parameters. Perusal from Table 1 showed that the flow property and packability of coground mixtures were improved compared to pure drug and control batch. This was due to the presence of flowable and plastically deforming behavior of PEG 4000. ${ }^{[48]}$

\section{Capillary melting point study}

A melting range of pure chlorzoxazone (197 to $\left.204^{\circ} \mathrm{C}\right)$ was observed. The melting range of all the samples of coground mixtures was observed between $51^{\circ} \mathrm{C}$ and $54^{\circ} \mathrm{C}$. This was due

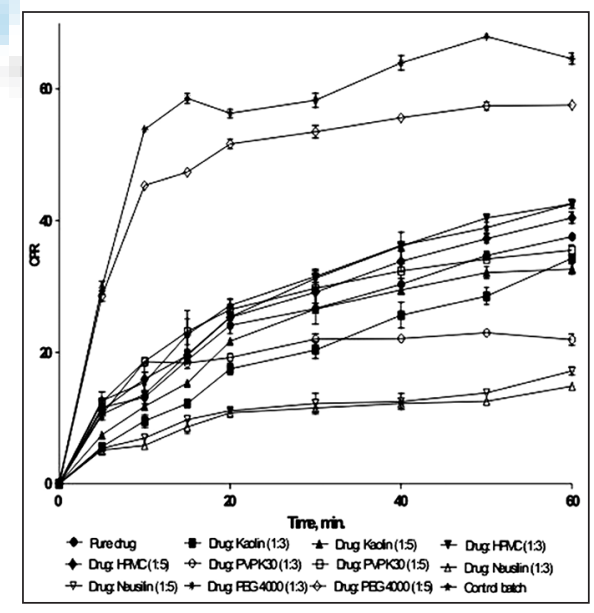

Figure 1: Dissolution profile of chlorzoxazone after grinding for one $\mathrm{h}$ with different excipients

\begin{tabular}{|c|c|c|c|c|c|c|c|c|}
\hline \multirow[t]{2}{*}{ Sample } & \multirow{2}{*}{$\begin{array}{c}\text { Grinding } \\
\text { time }\end{array}$} & \multirow{2}{*}{$\begin{array}{c}\text { Angle of } \\
\text { repose } \pm S D^{*}\end{array}$} & \multirow{2}{*}{$\begin{array}{c}\text { Carr's } \\
\text { index }(\%) \pm S D^{*}\end{array}$} & \multirow{2}{*}{$\begin{array}{l}\text { Hausner's } \\
\text { ratio } \pm S D^{*}\end{array}$} & \multicolumn{3}{|c|}{ Kawakita constants } & \multirow{2}{*}{$\begin{array}{c}\begin{array}{c}\text { Kuno's } \\
\text { constant }\end{array} \\
\text { K }\end{array}$} \\
\hline & & & & & a & b & $1 / b$ & \\
\hline Pure drug & - & $43.60 \pm 0.45$ & $37.14 \pm 0.2$ & $1.43 \pm 0.02$ & 0.49 & 0.10 & 9.9 & 0.32 \\
\hline \multirow[t]{2}{*}{ Control batch } & $3 \mathrm{~h}$ & $41.28 \pm 0.13^{b}$ & $38.31 \pm 1.2^{\mathrm{b}}$ & $1.51 \pm 1.63^{b}$ & 0.45 & 0.22 & 4.55 & 0.74 \\
\hline & $6 \mathrm{~h}$ & $40.06 \pm 1.03^{b}$ & $38.24 \pm 0.5^{\mathrm{b}}$ & $1.47 \pm 0.85^{\mathrm{b}}$ & 0.47 & 0.28 & 3.57 & 0.74 \\
\hline Coground mixture & $3 \mathrm{~h}$ & $17.04 \pm 1.12^{\mathrm{b}}$ & $13.4 \pm 0.32^{b}$ & $1.11 \pm 0.22^{b}$ & 0.26 & 0.41 & 2.43 & 1.08 \\
\hline Drug: PEG 4000 (1:3) weight ratio & $6 \mathrm{~h}$ & $19.88 \pm 1.05^{b}$ & $14.96 \pm 0.72^{b}$ & $1.21 \pm 1.05^{\mathrm{b}}$ & 0.29 & 0.37 & 2.7 & 0.96 \\
\hline
\end{tabular}

*Results are mean \pm SD of three observations, 'Significantly different compared to pure drug $(P<0.05)$, SD: Standard deviation, PEG: Polyethylene glycol 
to the presence of a large proportion of PEG 4000, which might dissolve the drug in it during heating. ${ }^{[49,50]}$

\section{Drug loading efficiency and \% yield}

The average percentage yield of coground mixture (1:3) obtained was 86 and $84.5 \%$ (after 3 and 6 h, respectively). The average drug content (loading) in coground mixture (1:3) was 24.43 and $24.21 \%$ (after 3 and $6 \mathrm{~h}$, respectively). The results indicated good loading efficiency and $\%$ yield.

\section{Selection of optimized batch}

In the case of coground sample of drug: PEG 4000 (1:3), mixture after $3 \mathrm{~h}$ grinding showed good flow, packability and morphological behavior compared with sample collected after 6 h. Hence, drug: PEG 4000 (1:3) mixture after 3 h grinding was selected for further evaluations.

\section{Heckel plot study of optimized batch of chlorzoxazone mixtures}

The true density of coground sample $\left(1.32 \mathrm{mg} / \mathrm{cm}^{3}\right)$ and pure drug $\left(0.95 \mathrm{mg} / \mathrm{cm}^{3}\right)$ suggested that, coground sample was improved in its packing and compaction properties compared to pure drug [Figure 3]. All the Heckel parameters are shown in Table 2. Larger the value of ' $\mathrm{K}$ ', greater was the plasticity in coground sample compared to pure drug. ${ }^{[1,52]}$ Initial nonlinear region followed by linearity in the graph [Figure 3] was a sign of plastic deformation in case of coground sample. Lower "A" value compared to pure drug suggested that, low compression pressure was required to obtain closest packing, fracturing its texture and densifying the fractured particles in case of coground sample. ${ }^{[23]}$ Lower values of yield strength $(\sigma 0)$ and yield pressure $(\mathrm{Py})$ in case of coground sample indicated that with a low applied pressure, a hard compact could be possible. Thus, Heckel plot data suggested that, coground material was fractured easily and new surface of particles produced might contributed to promoting plastic deformation under applied compression pressure. ${ }^{[47,52]}$ In the case of ground sample, effect of PEG 4000 (plastic material) on pellet formation was observed. More compressibility and densification of coground mixture in the presence of PEG 4000 was probably due to plastic deformation. ${ }^{[48]}$

\section{Tensile strength measurement}

The maximum tensile strength was obtained at compression force 9 ton. The tensile strength of pellets of coground mixture was much higher $(11.689 \pm 0.521 ; P<0.05)$ than the pure $\operatorname{drug}(5.708 \pm 0.121)$ [Figure 4] at the force of 9 ton. The high tensile strength of compacts was an indication of strong interparticulate bonding between particles of optimized batch compared to pure drug as well as control batch. ${ }^{[40]}$ In the case of coground mixture, during the compression process, surface melting of compacts containing PEG 4000 might easily occur, resulting in greater particle bonding and tensile strength. At higher force, melting of the particles and subsequent surface melting of compact become the probable predominant mechanism for volume reduction. ${ }^{[48]}$

\section{Elastic recovery}

Elastic recovery of compacts of samples was smaller (1.08 \pm 0.73 ; $P<0.05)$ than compacts of pure drug $(5.48 \pm 0.79)$. These findings suggested that particles were easily fractured, and the new surface of crystals produced might contribute to minimizing the elastic deformation after compression force was removed. ${ }^{[31]}$

\section{Aqueous solubility study}

Solubility data of drug and prepared samples were shown in Table 3 and represented graphically in Figure 5. The solubility of pure drug was found to be higher in distilled water and $\mathrm{pH}$ 6.8 buffer solutions, whereas low in $0.1 \mathrm{~N} \mathrm{HCl}, \mathrm{pH} 1.2$ and $\mathrm{pH}$ 4.5 buffer solutions. Control batch also behaved in the similar manner. Solubility of chlorzoxazone was found to be greater in coground sample over the solubility of pure drug as well as control batch too.

\section{Differential scanning calorimetry}

It was seen that there was no much difference in the melting endotherm of pure drug chlorzoxazone $\left(196.13^{\circ} \mathrm{C}\right)$ and control batches $\left(188.4^{\circ} \mathrm{C}\right)$ ground at 3 and $6 \mathrm{~h}$. It was an indication of absence of any polymorphic transformation. However, the heat of fusion in case of pure drug $(-431.28 \mathrm{~mJ})$ with compared to control batch at $3 \mathrm{~h}(-190.07 \mathrm{~mJ})$ and $6 \mathrm{~h}(-162.9 \mathrm{~mJ})$ was higher. This might be a reason of somewhat improved dissolution of the control batch than pure drug. ${ }^{[53]}$ The DSC-curves of pure component [Figure 6d] showed a single endothermic melting peak for PEG $4000\left(57.26^{\circ} \mathrm{C}\right)$. The DSC curve of the milled samples [Figure $6 \mathrm{f}$ and $\mathrm{g}$ ] exhibits a melting

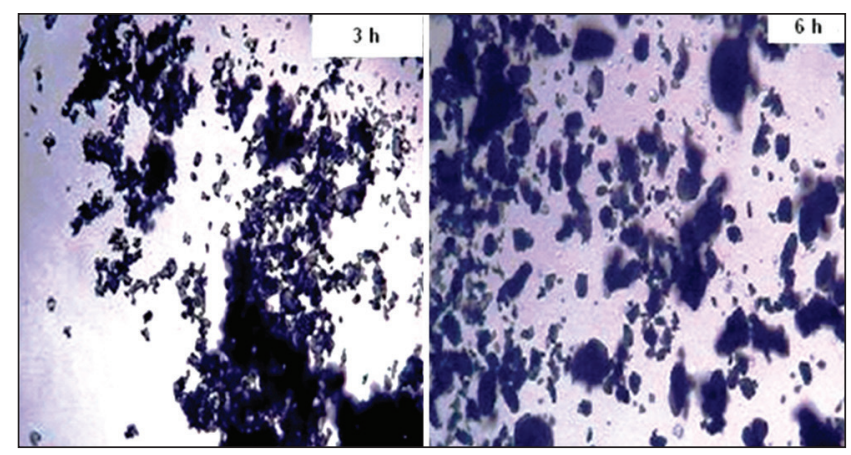

Figure 2: Photomicrograph of coground mixture of drug: PEG 4000

Table 2: Heckel plot parameters of chlorzoxazone samples

\begin{tabular}{lccccc}
\hline Batch & Yield pressure $\left(\mathbf{P}_{\mathrm{y}}\right)$ & Constant $(\mathbf{A})$ & Slope $(\mathbf{K})$ & Yield strength $\left(\boldsymbol{\sigma}_{0}\right)$ & $\boldsymbol{R}^{\mathbf{2}}$ \\
\hline Pure drug & 26.09 & 0.9924 & 0.038 & 8.7719 & 0.9724 \\
Coground mixture after 3 $\mathrm{h}$ & 2.082 & 0.6396 & 0.4803 & 0.6940 & 0.9817 \\
\hline
\end{tabular}


Table 3: Solubility data of chlorzoxazone from pure drug and ground drug in different solvents

\begin{tabular}{|c|c|c|c|c|c|}
\hline \multirow[t]{2}{*}{ Solvents } & \multicolumn{3}{|c|}{$\begin{array}{l}\text { Chlorzoxazone solubility }(\mathrm{mg} / \mathrm{ml}) \\
\text { Mean } \pm \mathrm{SD}^{*}\end{array}$} & \multicolumn{2}{|c|}{$\begin{array}{l}\text { Percentage of chlorzoxazone } \\
\text { solubility }\end{array}$} \\
\hline & Pure drug & Control batch & Coground drug ${ }^{b}$ & Control batch & Coground drug \\
\hline Distilled water & $1.008 \pm 0.05$ & $2.06 \pm 0.018$ & $3.12 \pm 0.046$ & 204.7 & 309.9 \\
\hline $0.1 \mathrm{~N} \mathrm{HCl}$ & $0.542 \pm 0.06$ & $0.984 \pm 0.05$ & $1.89 \pm 0.071$ & 181.5 & 349.1 \\
\hline pH 1.2 buffer & $0.55 \pm 0.051$ & $0.968 \pm 0.02$ & $1.58 \pm 0.091$ & 176.6 & 287.8 \\
\hline pH 4.6 buffer & $0.72 \pm 0.051$ & $1.143 \pm 0.08$ & $2.14 \pm 0.028$ & 159.2 & 297.6 \\
\hline pH 6.8 buffer & $1.018 \pm 0.01$ & $2.055 \pm 0.06$ & $3.24 \pm 0.074$ & 201.9 & 317.9 \\
\hline
\end{tabular}

*The results are the average of three determinations $(n=3),{ }^{b}$ Significantly different compared to pure drug $(P<0.05)$, SD: Standard deviation

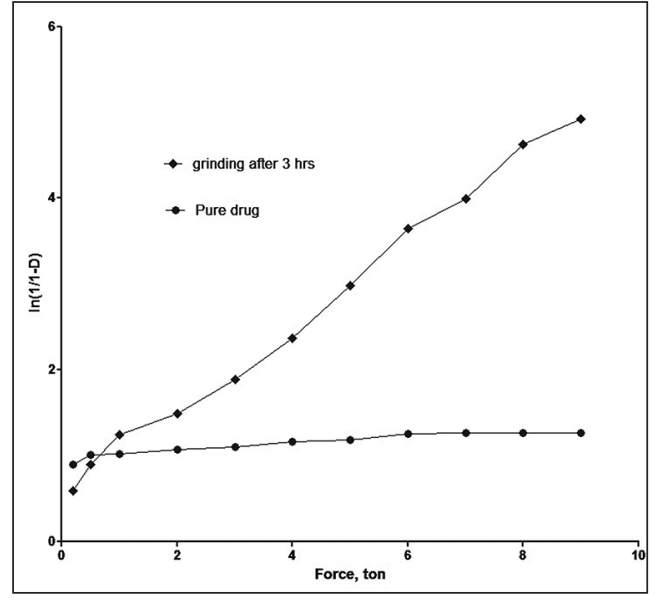

Figure 3: Heckel plot for chlorzoxazone and its optimized samples

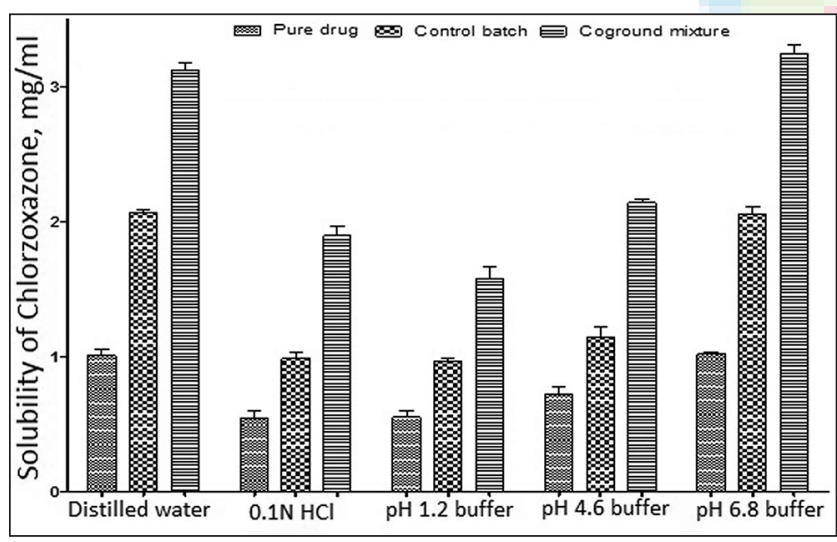

Figure 5: Solubility of chlorzoxazone from pure drug, control batch and coground mixture after $3 \mathrm{~h}$ (ratio, 1:3, \%w/w) in distilled water, 0.1 $\mathrm{N} \mathrm{HCl}$ and buffer solution of $\mathrm{pH} 1.2,4.6$ and 6.8 (mean \pm S.D.; $n=3$ )

endotherm of $48.8^{\circ} \mathrm{C}$ and $48.95^{\circ} \mathrm{C}$, respectively, which was very near to the melting peak of PEG 4000. A similar result was obtained for the physical mixture [Figure 6e] where melting peak of chlorzoxazone could not be recorded. This behavior was due to the slow dissolution of chlorzoxazone in the melt of carrier on heating and thereafter the stabilization of solid drug particles in a metastable form, therefore no distinct endothermic event could be observed for the drug in drugpolymer milled mixture. ${ }^{[49,50]}$ The peak of PEG 4000 in the DSC-curve of coground samples was broadened compared to the melting peak of PEG 4000, which indicated that the carrier weakly interacted with chlorzoxazone. Similar observations

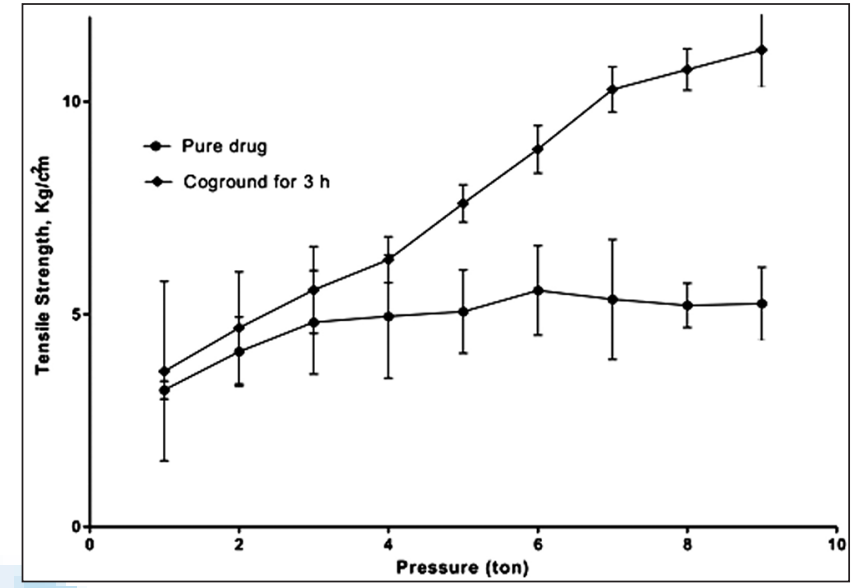

Figure 4: Pressure- tensile strength relation between chlorzoxazone and its prepared samples

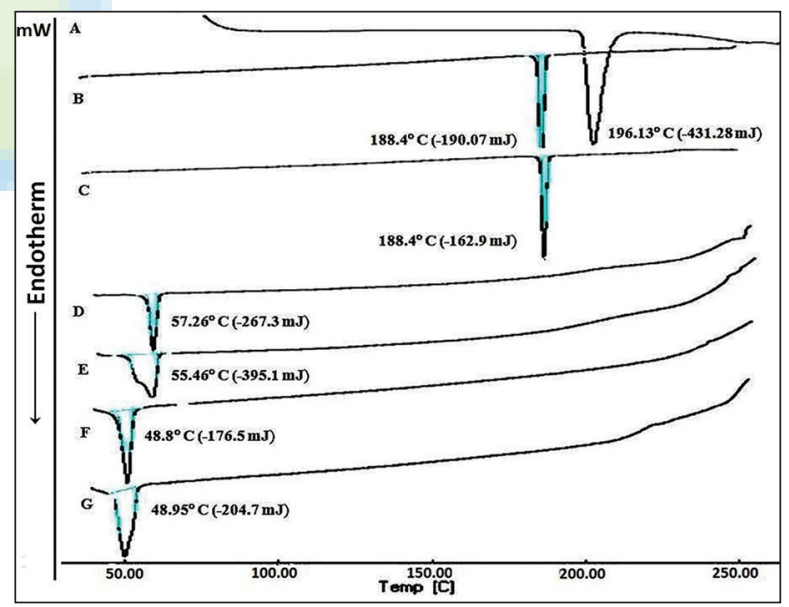

Figure 6: Differential scanning calorimetry spectra of (a) pure chlorzoxazone, (b) control batch after $3 \mathrm{~h}$ (c) control batch after $6 \mathrm{~h}$, (d) polyethylene glycol (PEG 4000), (e) physical mixture of drug and polymer in 1:3 ratio, (f) coground mixture of drug: PEG 4000 (1:3) after $3 \mathrm{~h}$, and $(\mathrm{g})$ coground mixture of drug: PEG 4000 (1:3) after $6 \mathrm{~h}$

were reported by Rodriguez et al. ${ }^{[49]}$ for diclofenac/PEG 4000 systems. Also in this system, only a broad endotherm was observed corresponding to the monotectic melting (some degrees below the melting peak of the pure PEG 4000). ${ }^{[49,50]}$ As such polymers are not highly ordered and always contain some "structural voids" it is likely that the amount of the drug that dissolved in melt was entrapped in such areas after cooling and crystallized in the carrier. ${ }^{[50]}$ 


\section{Fourier transform infra-red spectroscopy}

In case of coground samples of chlorzoxazone, Fourier transform infra-red (FT-IR) spectroscopy study of pure chlorzoxazone in Figure 7 showed characteristic peaks at $3146.68 \mathrm{~cm}^{-1}(\mathrm{~N}-\mathrm{H}$ stretch), $3052.24 \mathrm{~cm}^{-1}$ (Aromatic Hydrocarbon), 1615.69 $\mathrm{cm}^{-1}\left(\mathrm{C}=\mathrm{C}\right.$ Stretch) and $732.09 \mathrm{~cm}^{-1}$ (C-Cl linkage). FT-IR spectra of PEG 4000 showed peaks at $2950-2750 \mathrm{~cm}^{-1}(\mathrm{C}-\mathrm{H}$ stretch) and $1466.34 \mathrm{~cm}^{-1}$ (C-H bending) and $1350-1000 \mathrm{~cm}^{-1}$ (C-O stretching). From Figure 7, it was seen that all peaks of chlorzoxazone were present in control batch, physical mixture of drug-polymer and ground drug in presence of PEG 4000. Thus, it was concluded that there was no any chemical reaction found between drug and polymer. As well as, there was no sign of any polymorphic changes.

\section{Powder X-ray diffractometry}

In case of coground mixture of chlorzoxazone, powder X-ray diffractometry (pXRD) of chlorzoxazone revealed high intensity reflections with characteristic sharp peaks at $19.92^{\circ}, 27.49^{\circ}, 12.83^{\circ}$, $13.82^{\circ}, 25.23^{\circ}, 17.77^{\circ}$ and $25.79^{\circ}(2 \theta)$. The peak at $19.92^{\circ}(2 \theta)$ was used to compare the pXRD patterns. PEG 4000 exhibited a distinct pattern with diffraction peaks at $23.35^{\circ}$ and $19.23^{\circ}(2 \theta)$ [Figure 8]. The physical mixture showed characteristic peaks of pure components at identical angles, which proved that no interactions took place during mixing [Figure 8]. Here, the peaks of drug are of slightly low intensity in the physical mixture also. This might be due to a lower concentration of drug in the physical mixture (1:3). All the peaks were present in the diffractogram of control batches but with very low intensity than that of pure drug powder. Moreover, the same peaks of drug were also appeared in the milled drug in presence of polymer at 3 and $6 \mathrm{~h}$, but the intensity was again very much reduced compared to pure drug. This was almost amorphous in nature. ${ }^{[53]}$ This indication further supported the absence of any chemical interaction between drug and polymer. Moreover, it also enhanced the dissolution of drug. ${ }^{[54]}$

\section{Scanning electron microscopy}

In the study of cogrinding with PEG 4000, scanning electron microscopy (SEM) photograph showed crystalline nature of drug at the initial stage. Control batch showed aggregation of particles resulting in to somewhat bigger particles due to charge generation. ${ }^{[55]}$ Microscopic study in Figure 2 also showed that the coground sample after $3 \mathrm{~h}$ was reduced in its particle size, whereas particles after grinding for $6 \mathrm{~h}$ were somewhat bigger in its size. The same kind of behavior was noticed in SEM images also. On grinding in the presence of PEG 4000, the particle size was increased [Figure 9]. This might be because of a generation of the little amount of local heat on grinding, which melted PEG 4000 to a little extent. Due to this, the polymer dissolved in a part and adsorbed at the crystalline surface of drug and formed bigger particles. ${ }^{[48]}$ This also increased amorphization of chlorzoxazone. ${ }^{[50]}$ In Figure $9 \mathrm{e}$, the size of the particle was still bigger due to more layering of PEG 4000 onto the drug crystals.

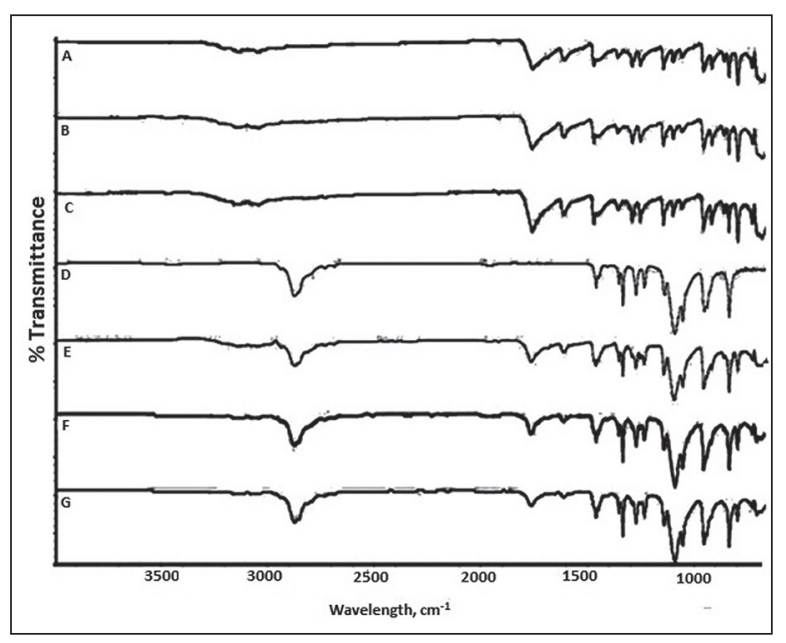

Figure 7: Fourier transform infra-red analysis of (a) chlorzoxazone pure drug, (b) ground drug after $3 \mathrm{~h}$, (c) ground drug after $6 \mathrm{~h}$, (d) polyethylene glycol 4000, (e) physical mixture of drug: Polymer in 1:3 ratio, $(\mathrm{f})$ coground drug with polymer in $1: 3$ ratio after $3 \mathrm{~h}$ and (g) coground drug with polymer in 1:3 ratio after $6 \mathrm{~h}$

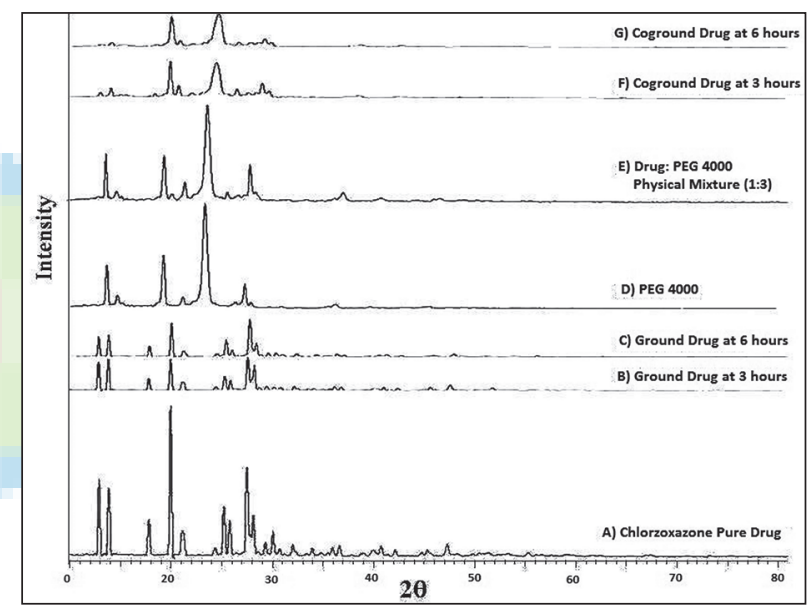

Figure 8: Powder X-ray diffractometry pattern of coground chlorzoxazone

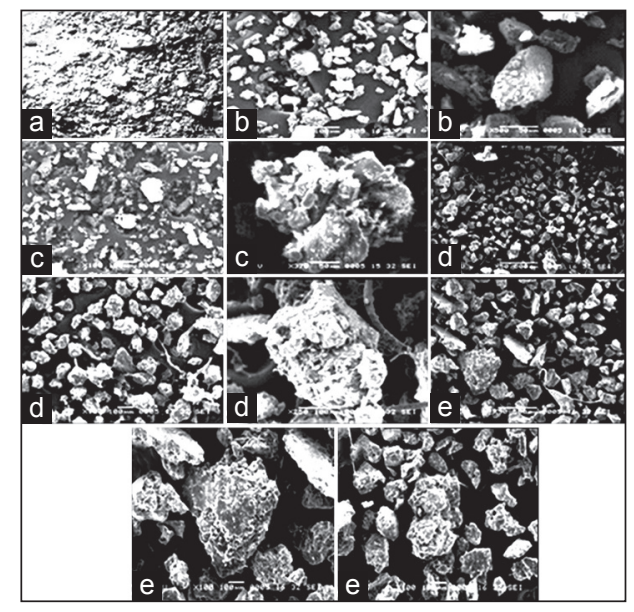

Figure 9: Scanning electron microscopy analysis of (a) chlorzoxazone pure drug, (b) control batch at $3 \mathrm{~h}$, (c) control batch at $6 \mathrm{~h}$, (d) coground CHLOR: Polyethylene glycol (PEG 4000) (1:3) at $3 \mathrm{~h},(\mathrm{e})$ coground CHLOR: PEG 4000 (1:3) at $6 \mathrm{~h}$ 
Preparation of directly compressible tablets of chlorzoxazone and prepared mixture

Tablets containing ground mixture equivalent to $125 \mathrm{mg}$ chlorzoxazone were prepared by direct compression using different formulation excipients shown in Table 4. Coground mixture was sieved to achieve a similar particle size distribution (no. 80) for each batch and other formulation excipients were added in it. All the ingredients for tablets prepared from coground mixture were weighed separately, mixed properly in ' $\mathrm{V}$ ' cone blender. The material for each tablet was weighed, introduced manually into the die and compressed in tablet machine using round-shaped, $15 \mathrm{~mm}$ flat, round punches. Here, PEG 4000 is a directly compressible material undergoing plastic deformation. Microcrystalline cellulose (MCC) was required only as filler. At the same time, directly compressible tablets of pure drug required a large quantity of MCC for good hardness without lamination. It was a sign of better compression properties of coground mixture. The evaluation parameters of prepared tablets are given in Table 5.

In vitro dissolution of prepared mixtures and dosage forms of chlorzoxazone

The dissolution medium was $900 \mathrm{ml}$ buffer phosphate (pH 6.8) equilibrated to $37^{\circ} \mathrm{C} \pm 0.5^{\circ} \mathrm{C}$. Peddles/baskets were rotated at $50 \mathrm{rpm}$. The concentrations of chlorzoxazone in the solutions were determined by UV spectrophotometer at $280 \mathrm{~nm}$ by diluting with phosphate buffer $\mathrm{pH} 6.8$ using same media as blank. All the determinations were performed in triplicate. Dissolution profiles were studied at every hour during grinding, till the constant rate of dissolution was achieved [Figure 10]. From the dissolution profile, it was seen that, after $3 \mathrm{~h}$ grinding, an increment in the rate of dissolution was almost negligible. Hence, dissolution after 3 and $6 \mathrm{~h}$ were selected for further calculations. Figure 10 indicated that, cumulative percentage release at $1 \mathrm{~h}$ was increased to $90 \%$ from the sample collected after $3 \mathrm{~h}$ grinding in the presence of PEG 4000. Further grinding did not increase the rate of drug dissolution, hence, grinding of drug with PEG 4000 for $3 \mathrm{~h}$ was considered as the optimized sample for formulation as it also showed good

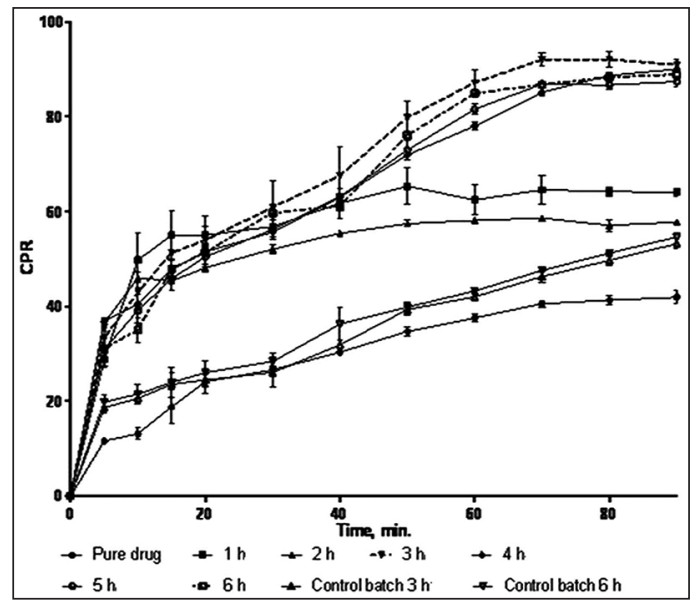

Figure 10: Comparative in vitro drug release profile at different time intervals of pure drug, control batch and coground sample physico-mechanical properties. In Figure 11, a comparison of dissolution profile of ground sample for $3 \mathrm{~h}$ and tablet prepared from the same powder mixture is presented. Tablets prepared from coground mixture also showed $>90 \%$ drug release within $1 \mathrm{~h}$. Whereas, tablets prepared from pure drug showed only $32 \%$ drug release at the end of $1 \mathrm{~h}$. Moreover, physical mixture of drug and PEG 4000 showed only $45 \%$ drug release after 1 h. It indicated that, drug was influenced by cogrinding in presence of polymer and converted into amorphous form, which resulted in a higher dissolution of drug. ${ }^{[56]}$ Figure 11 is indicating the release profiles of drug, physical mixture and prepared dosage forms.

\begin{tabular}{lcc}
$\begin{array}{l}\text { Table 4: Formulation of directly compressible } \\
\text { tablet of chlorzoxazone from coground mixture } \\
(\mathbf{1 : 3 , \% ~ w / w ) ~}\end{array}$ & \\
\hline Formulation and evaluation & Pure drug & $\begin{array}{c}\text { Coground mixture } \\
(\mathbf{1}: 3, \% \text { w/w) }\end{array}$ \\
\hline Chlorzoxazone, mg & 125 & $\begin{array}{c}511.67 \mathrm{mg} \\
\text { (equivalent to } 125 \mathrm{mg} \\
\text { chlorzoxazone) }\end{array}$ \\
Kyron T-314, mg, (10\%) & & 65 \\
Magnesium stearate, mg, (1\%) & 12 & 6.5 \\
Talc, mg, (2\%) & 1.3 & 13 \\
Aerosil, mg, (0.5\%) & 2.5 & 3.25 \\
MCC, mg & 0.6 & 50.58 \\
Lactose anhydrous, $\mathrm{mg}$ & 75 & - \\
Total weight of tablet, $\mathrm{mg}$ & 33.6 & 650 \\
\hline
\end{tabular}

MCC: Microcrystalline cellulose

Table 5: Evaluation parameters of prepared tablets

\begin{tabular}{|c|c|c|}
\hline \multirow[t]{2}{*}{ Parameters } & \multicolumn{2}{|c|}{ Tablets equivalent of drug from } \\
\hline & Pure drug & Coground mixture \\
\hline Hardness ${ }^{*}, \mathrm{~kg} / \mathrm{cm}^{2} \pm \mathrm{SD}^{*}$ & $5.3 \pm 0.67$ & $6.8 \pm 0.33$ \\
\hline Friability, \% & 0.51 & 0.19 \\
\hline $\mathrm{DT}^{*}, \mathrm{~s} \pm \mathrm{SD}^{*}$ & $4.51 \pm 1.33$ & $5.26 \pm 1.44$ \\
\hline Diameter ${ }^{*}, \mathrm{~mm} \pm \mathrm{SD}^{*}$ & $6.01 \pm 0.005$ & $6.07 \pm 0.003$ \\
\hline Thickness ${ }^{*}, \mathrm{~mm} \pm \mathrm{SD}^{*}$ & $3.21 \pm 0.01$ & $3.19 \pm 0.03$ \\
\hline Weight variation* ${ }^{*} \mathrm{mg} \pm \mathrm{SD}^{*}$ & $248.3 \pm 2.17$ & $645.7 \pm 3.51$ \\
\hline
\end{tabular}

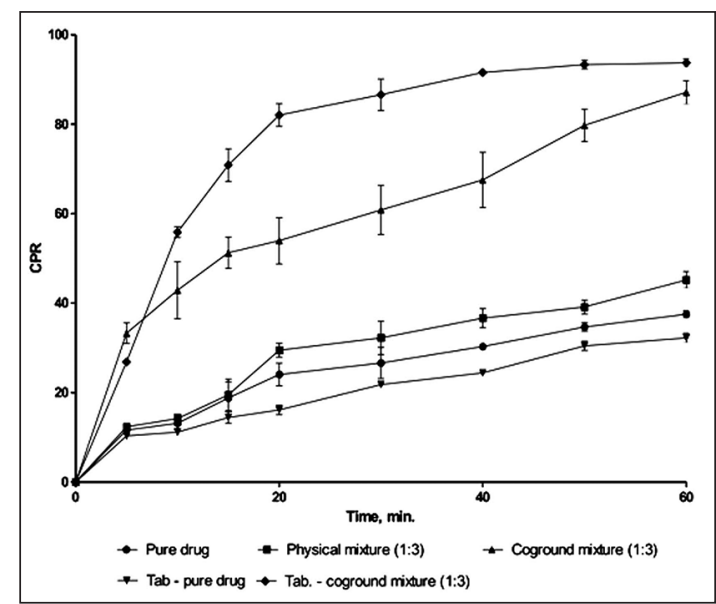

Figure 11: Dissolution profiles of chlorzoxazone, physical mixture of drug: Polyethylene glycol 4000, coground mixture and dosage forms 


\begin{tabular}{|c|c|c|c|c|c|c|}
\hline \multirow[t]{2}{*}{ Sample } & \multicolumn{2}{|c|}{$\% \mathrm{DE}_{10}$} & \multicolumn{2}{|c|}{$\mathrm{DP}_{5 \mathrm{~min}}, \%$} & \multicolumn{2}{|c|}{$t_{50}, \min$} \\
\hline & $P$ & $T$ & $P$ & $T$ & $P$ & $T$ \\
\hline $\begin{array}{l}\text { Pure drug } \\
\text { Coground mixture }\end{array}$ & $\begin{array}{c}8.76 \\
35.71\end{array}$ & $\begin{array}{l}34.10 \\
34.10\end{array}$ & $\begin{array}{l}11.00 \\
33.31\end{array}$ & $\begin{array}{c}13.6 \\
26.85\end{array}$ & $\overline{14.00}$ & $9 . \overline{00}$ \\
\hline
\end{tabular}

P: Powder dissolution, T: Tablet dissolution, DE: Dissolution efficiency, DP: Dissolution percent

\begin{tabular}{|c|c|c|c|c|}
\hline \multirow[t]{2}{*}{ Sample } & \multicolumn{2}{|c|}{$f_{2}$} & \multicolumn{2}{|c|}{ MDT, min } \\
\hline & Sample & Tablet & Sample & Tablet \\
\hline $\begin{array}{l}\text { Pure drug } \\
\text { Coground mixture }\end{array}$ & $-{ }^{-}$ & $\overline{16.49^{*}}$ & $\begin{array}{l}19.93 \\
3.62\end{array}$ & $\begin{array}{l}21.85 \\
11.16\end{array}$ \\
\hline
\end{tabular}

*Dissimilarity between dissolution profiles, MDT: Mean dissolution time

\section{Dissolution parameters study}

The results indicated in Table 6 that, highest \%DE 10 min was shown by coground mixture, which was an indication of higher amorphization of drug. ${ }^{[45]}$

\section{Statistical analysis of dissolution profiles}

Results of similarity factor and MDT are shown in Table 7. Dissolution profiles of coground mixture and prepared tablets showed dissimilarity with pure drug. Results of MDT indicate the increased dissolution rate of prepared samples and its formulations than pure drug. ${ }^{[38]}$

\section{Stability study}

The amount of chlorzoxazone in the coground mixture was found $23.92 \pm 0.38 \mathrm{mg}$, respectively after the storage. The reduction in drug content was very negligible (1.27\%). The dissolution profile of stored coground mixture [Figure 11] was also similar compared to samples soon after the preparation. The statistical analysis also proved sameness in dissolution profiles $\left(f_{2}=67.99\right)$. Similar dissolution profiles of dosage forms $\left(f_{2}=88.16\right)$ prepared from coground mixture were found before and after the stability study. The FT-IR and DSC spectra proved no physical and chemical interaction occurred during the stability study in the samples (data not shown). From the above findings for coground mixture of drug: PEG 4000 (1:3, $\% \mathrm{w} / \mathrm{w})$, it was suggested that, drug was in a stable form into the prepared samples.

\section{CONCLUSION}

In the present study, physicochemical and micromeritic property of chlorzoxazone was improved using cogrinding. Out of several excipients, only PEG 4000 could generate amorphization in the drug in 1:3 weight ratio. Flow property and compressibility of coground mixture were remarkably improved compared to pure drug due to spherical and equidimensional shape of particles. Melting point of coground mixture was near to the melting point of PEG 4000, which confirmed the dissolution of the drug in PEG 4000 at the time of melting. The compatibility also confirmed using FT-IR analysis. Lower peak intensities and different angle of diffractions further in pXRD analysis confirmed amorphization of the drug due to cogrinding that again improved the rate of dissolution of the drug to almost 2.5 times. Tablets prepared from coground mixture showed good strength compared to pure drug. Higher aqueous solubility of coground mixture in all the buffer solutions was due to amorphization of drug as well as the presence of PEG 4000. The stability study of coground mixture and their dosage form showed its stable nature.

\section{ACKNOWLEDGMENT}

Authors are very much obliged to Arti Drugs Ltd., Mumbai, India and Gangwal Chemicals Pvt. Ltd., Mumbai, India for providing gift samples of Chlorzoxazone and Nusilin US2 BP, respectively. Authors are also grateful to Dr. Mukesh Gohel, Ahmedabad, India and Dr. CVS Subrahmanyam, Hyderabad, India for their constant guidance and support.

\section{REFERENCES}

1. Vogt M, Kunath K, Dressman JB. Dissolution improvement of four poorly water soluble drugs by cogrinding with commonly used excipients. Eur J Pharm Biopharm 2008;68:330-7.

2. Wang Q, Li S, Chi X, Fan X, Li C. Dissolution improvement and stabilization of Ibuprofen by co-grinding in a $\beta$-cyclodextrine ground complex. Asian J Pharm Sci 2010;5:185-90.

3. Raval MK, Bagda AA, Patel JM, Paun JS, Chaudhari KR, Sheth NR. Preparation and evaluation of sustained release nimesulide microspheres using response surface methodology. J Pharm Res 2010;3:581-6.

4. Di Martino P, Scoppa M, Joiris E, Palmieri GF, Andres C, Pourcelot $\mathrm{Y}$, et al. The spray drying of acetazolamide as method to modify crystal properties and to improve compression behaviour. Int J Pharm 2001;213:209-21.

5. Vyas A, Saraf S, Saraf S. Cyclodextrin based novel drug delivery systems. J Incl Phenom Macrocycl Chem 2008;62:23-42.

6. Shah PP, Mashru RC. Development and evaluation of artemether taste masked rapid disintegrating tablets with improved dissolution using solid dispersion technique. AAPS PharmSciTech 2008;9:494-500.

7. Choil WS, Kwak SS, Kim HI. Improvement of bioavailability of water insoluble drugs: Potential of nano-sized grinding technique. Asian J Pharm Sci 2006;1:27-30.

8. Balani PN, Ng WK, Tan RB, Chan SY. Influence of excipients in comilling on mitigating milling-induced amorphization or structural disorder of crystalline pharmaceutical actives. J Pharm Sci 2010;99:2462-74.

9. Patterson JE, James MB, Forster AH, Lancaster RW, Butler JM, Rades T. Preparation of glass solutions of three poorly water soluble drugs by spray drying, melt extrusion and ball milling. Int J Pharm 2007;336:22-34.

10. Shakhtshneider TP, Dane F, Capet F, Willart JF, Descamps M, Paccou L, et al. Grinding of drugs with pharmaceutical excipients at cryogenic temperatures. Part II. Cryogenic grinding of indomethacin polyvinyl pyrrolidone mixtures. J Therm Anal Chem 2007;89:709-15. 
11. Bahl D, Bogner RH. Amorphization of Indomethacin by CoGrinding with Neusilin US2: Amorphization kinetics, physical stability and mechanism. Pharm Res 2006;23:2317-25.

12. USP 27-NF 24. Asian edition. MD: United State Pharmacopeial Convention, Inc.; 2009. p. 440.

13. Available from: http://www.drugbank.ca/drugs/DB00356. 2011, cited 2014 Jan 10.

14. Florey C. Analytical Profiles of Drug Substances. Vol. 16. London: Academic Press Inc.; 1987.

15. Das SK, Roy S, Kalimuthu Y, Khanam J, Nanda A. Solid dispersions: An approach to enhance the bioavailability of poorly water-soluble drugs. Int J Pharmacol Pharm Technol 2011;1:37-46.

16. Seth NS. Formulation and evaluation of solid dispersion of olanzepine. Int J Pharm Sci Res 2011;2:691-7.

17. Vadher AH, Parikh JR, Parikh RH, Solanki AB. Preparation and characterization of co-grinded mixtures of aceclofenac and neusilin US2 for dissolution enhancement of aceclofenac. AAPS PharmSciTech 2009;10:606-14.

18. Zhang L, Chai G, Zeng X, He H, Xu H, Tang X. Preparation of fenofibrate immediate-release tablets involving wet grinding for improved bioavailability. Drug Dev Ind Pharm 2010;36:1054-63.

19. Basalious EB, Shawky N, Badr-Eldin SM. SNEDDS containing bioenhancers for improvement of dissolution and oral absorption of lacidipine. I: Development and optimization. Int J Pharm 2010;391:203-11.

20. Aulton ME. Pharmaceutics: The Design and Manufacture of Medicines. $1^{\text {st }}$ ed. London: Churchill Livingstone; 2002.

21. Vela MT, Fernandes AM, Rabasco AM. Rheological study of lactose coated with acrylic resins. Drug Dev Ind Pharm 1990;16:295-300.

22. Lachman L, Libermann HA, Kanig JL. The Theory and Practice of Industrial Pharmacy. $3^{\text {rd }}$ ed. Bombay: Varghese Publishing House; 1991.

23. Kawashima Y. Development of spherical crystallization technique and its application to pharmaceutical systems. Arch Pharm Res 1984;7:145-51

24. Yu $A B$, Hall JS. Packing of fine powders subjected to tapping. Powder Technol 1994;78:247-56.

25. Denny P. Compaction equations: A comparison of the Heckel and Kawakita equations. Powder Technol 2002;127:162-72.

26. Kawakita K, Ludde KH. Some considerations on powder equations. Powder Technol 1971;4:61-8.

27. Chavda V, Maheshwari RK. Tailoring of ketoprofen particle morphology via novel crystallo-co-agglomeration technique to obtain a directly compressible material. Asian J Pharm 2008;2:61-7.

28. Patra N, Singh SP, Hamd P, Vimladevi M. A systematic study on micromeritic properties and consolidation behavior of the terminaliya Arjuna bark powder for processing into tablet dosage from. Int J Pharm Excip 2007;6:6-7.

29. Chaulang G, Patil K, Ghodke D, Khan S. Preparation and characterization of solid dispersion tablet of furosemide with crospovidone. Res J Pharm Technol 2008;1:386-9.

30. Maghsoodi M, Taghizadeh O, Martin GP, Nokhodchi A. Particle design of naproxen-disintegrant agglomerates for direct compression by a crystallo-co-agglomeration technique. Int $\mathrm{J}$ Pharm 2008;351:45-54.

31. Raval MK, Sorathiya KR, Chauhan NP, Patel JM, Parikh RK, Sheth NR. Influence of polymers/excipients on development of agglomerated crystals of secnidazole by crystallo-coagglomeration technique to improve processability. Drug Dev Ind Pharm 2013;39:437-46.
32. Rundick A, Hunter AR, Holden FC. An analysis of the diametral compression test and the applicability to plastically deforming materials. Mater Res Stand 1963;3:283-9.

33. Armstrong NA, Haines-Nutt RF. Elastic recovery and surface area changes in compacted powder systems. Powder Technol 1974;9:287-90.

34. Armstrong NA, Palfrey LP. The effect of machine speed on the consolidation of four directly compressible tablet diluents. J Pharm Pharmacol 1989;41:149-51.

35. Gohel MC, Jogani PD. An investigation of the direct compression characteristics of co processed lactose microcrystalline cellulose using statistical design. Pharm Technol 1999;22:54-62.

36. Shivakumar HG, Ramalingaraju G. Influence of solvents on crystal habit and properties of paracetamol crystals. Indian J Pharm Sci 1999;61:100-4.

37. Vyazovkin S. Thermal analysis. Anal Chem 2008;80:4301-16.

38. Patel R, Bhimani D, Patel J, Patel D. Solid-state characterization and dissolution properties of ezetimibe-cyclodextrins inclusion complexes. J Incl Phenom Macrocycl Chem 2008;60:241-51.

39. Kumar S, Chawla G, Bansal AK. Role of additives like polymers and surfactants in the crystallization of mebendazole. Yakugaku Zasshi 2008;128:281-9.

40. Maghsoodi $M$, Hassan-Zadeh D, Barzegar-Jalali $M$, Nokhodchi A, Martin G. Improved compaction and packing properties of naproxen agglomerated crystals obtained by spherical crystallization technique. Drug Dev Ind Pharm 2007;33:1216-24

41. Bandyopadhyay R, Selbo J, Amidon GE, Hawley M. Application of powder X-ray diffraction in studying the compaction behavior of bulk pharmaceutical powders. J Pharm Sci 2005;94:2520-30.

42. Rivera $A B$, Hernández RG, Novoa de Armas H, Elizástegi DM, Losada MV. Physico-chemical and solid-state characterization of secnidazole. Farmaco 2000;55:700-7.

43. Mallick S. Effect of solvent and polymer additives on crystallization. Indian J Pharm Sci 2004;66:142-7.

44. United States Pharmacopoeia 29. Rockville, Maryland, USA United States Pharmacopoeial Convention Inc.; 2006. p. 576.

45. Dahiya S. Studies on formulation development of a poorly watersoluble drug through solid dispersion technique. Thai J Pharm Sci 2010;34:77-87.

46. Anderson NH, Bauer M, Boussac N, Khan-Malek R, Munden P, Sardaro M. An evaluation of fit factors and dissolution efficiency for the comparison of in vitro dissolution profiles. J Pharm Biomed Anal 1998;17:811-22.

47. Moore JW, Flanner $\mathrm{HH}$. Mathematical comparison of curves with an emphasis on in vitro dissolution profiles. Pharm Technol 1996;20:64-74.

48. Lin CW, Chain TM. Compression behavior and tensile strength of heat-treated polyethylene glycols. Int J Pharm 1995;118:169-79.

49. Rodriguez L, Cavallari C, Passerini N, Albertini B, GonzálezRodríguez M, Fini A. Preparation and characterization by morphological analysis of diclofenac/PEG 4000 granules obtained using three different techniques. Int J Pharm 2002;242:285-9.

50. Bartsch SE, Griesser UJ. Physicochemical properties of the binary system glibenclamide and polyethylene glycol 4000. J Therm Anal Calorim 2004;77:555-69.

51. Barot BS, Parejiya PB, Patel TM, Parikh RK, Gohel MC. Development of directly compressible metformin hydrochloride by the spray-drying technique. Acta Pharm 2010;60:165-75.

52. Kawashima $Y$, Imai $M$, Takeuchi $H$, Yamamoto $H$, Kamiya $K$, Hino T. Improved flowability and compactibility of spherically agglomerated crystals of ascorbic acid for direct tableting designed by spherical crystallization process. Powder Technol 2003;130:283-9. 
53. Wang Q, Sanming LI, Che X, Fan X, Chaojie LI. Dissolution improvement and stabilization of ibuprofen by co-grinding in a $\beta$-cyclodextrin ground complex. Asian J Pharm Sci 2010;5:188-93.

54. Bhole PG, Patil VR. Enhancement of water solubility of felodipine by preparing solid dispersion using poly-ethylene glycol 6000 and poly-alcohol. Asian J Pharm 2009;3:240-4.

55. Subrahmanyam CV. Essentials of Physical Pharmacy. $1^{\text {st }}$ ed. New Delhi: Vallabh Prakashan; 2010.
56. Vogt M, Kunath K, Dressman JB. Dissolution enhancement of fenofibrate by micronization, cogrinding and spray-drying: Comparison with commercial preparations. Eur J Pharm Biopharm 2008;68:283-8.

How to cite this article: Raval MK, Patel JM, Parikh RK, Sheth NR. Dissolution enhancement of chlorzoxazone using cogrinding technique. Int J Pharma Investig 2015;5:247-58.

Source of Support: Nil. Conflict of Interest: None declared. 